\title{
Measuring capital intensity in South African companies listed in the Industrial Section of the Johannesburg Stock Exchange (JSE)
}

\author{
J.H. Burger \& W.D. Hamman \\ Graduate School of Business, University of Stellenbosch, P.O. Box 610, Bellville, 7353 South Africa
}

Received August 1999

\begin{abstract}
The authors investigated selected listed companies in the Industrial Section of the JSE to determine the degree of capital-intensity of the selected companies. This is done by calculating various measures of capital intensity of the companies concerned and ranking the companies accordingly. Statistical analyses were done to investigate for significant differences between various measures, as well as between and within sectors of the Industrial Section of the JSE. It was found that overall there are no significant differences between the rankings of the ratios. Between sectors overall, there are significant differences between the rankings of ratios. Based upon years, however, there are no significant differences. Within sectors and between sectors per ratio, there are significant differences between the rankings of the ratios. From the analyses it is clear that the sectors are not homogeneously compiled, but are quite diversified. The measures of capital-intensity used also do not explain the same phenomenon. It has also been found that some companies display a dualism in that they are capitalintensive on some measures and capital-unintensive on others.
\end{abstract}

\section{Introduction}

It is common knowledge that sales or tumover is supported by the assets of a company. Should the company function at full capacity and wish to increase sales, it would require an increase in assets. Furthermore, it is also generally accepted that the assets of a company have to be maintained in order to maintain the level of output. Failure to do so would result in a decrease in the output of the particular company over time. This has obvious implications for the earnings potential of a company and is therefore closely monitored by investment analysts.

Shapiro (1982: 399) confirms the above by stating that investment occurs to increase the assets of a company as a greater output requires an increase in assets. He acknowledges that companies would be able to increase their output by using the existing assets more productively, but there are limits to what extent this could occur. Furthermore, the type of industry will also influence the size of assets required to produce a certain level of output. It is obvious that a company in the manufacturing industry will need more assets than a company in the services industry to generate a similar level of turnover. The use of assets and turnover not only indicates the extent to which a company needs assets to generate turnover, but is also an indication of how efficiently the assets have been used to generate turnover.

Capital intensity, which is the term for the above phenomenon, is a macro-economic term. It is interesting to note that production in South Africa increasingly becomes capital intensive at the same time capital becomes less available (Dornbusch \& Fischer, 1998: 64). It is the intention of this article to investigate selected listed companies in the Industrial Section of the Johannesburg Stock Exchange (JSE) to determine the degree of capital-intensity of the selected companies. This will be done by calculating various measures of capital-intensity of the companies concerned and ranking the companies accordingly. The research is necessary to gain understanding of the underlying measures of capital-intensity and to identify certain trends, if possible.
The following hypotheses are tested in this article (subsamples are as set out in the third section):

$\mathrm{H}_{1}$ : There are significant differences between the rankings of the ratios for each sub-sample.

$\mathrm{H}_{2}$ : There are significant differences between the rankings of the ratios based on sectors per sub-sample.

$\mathrm{H}_{3}$ : There are significant differences between the rankings of the ratios based on years per sub-sample.

$\mathrm{H}_{4}$ : There are significant differences in the rankings of the ratios between sectors per sub-sample.

$\mathrm{H}_{5}$ : There are significant differences between the rankings of the ratios within sectors per sub-sample.

The following section will cover the literature survey, while the third part will cover the research method. The fourth part will cover the results of the survey and the fifth part contains the conclusion.

\section{Literature survey}

Garrison \& Noreen (1997: 300) state that several factors have resulted in a shift toward greater fixed costs and less variable costs in organisations. This shift in cost structure has had an impact on product contribution margin ratios, on the breakeven point, and on other cost-volume-profit factors in automated (capital-intensive) companies. Although there are many benefits to be derived from automation, certain risks are introduced when a company becomes more capital-intensive. According to Garrison \& Noreen, the contribution margin ratio for a given product will be relatively higher for a capitalintensive company as the variable costs in an automated company will tend to be lower than in a labour-intensive company. Due to the higher fixed costs of a capital-intensive company, both the operating leverage and break-even point will be higher than for a labour-intensive company. As a result of this, the margin of safety at a given level of sales will be lower, and the latitude available to management in terms of economic stress will tend to be less for the capitalintensive company. In periods of increasing/decreasing sales, net income will tend to increase/decrease rapidly for the 
capital intensive company, while the volatility of this net income with changes in sales will tend to be greater.

Dornbusch \& Fischer (1998: 64) showed that South Africa experienced a structural decline in the growth of real fixed investment spending and eventually a static real fixed capital stock, while more and more investment was required to provide a given number of jobs. In other words, production became increasingly capital-intensive in a country in which capital is in short supply. They also showed that the fixed capital investment per worker at constant 1985 prices increased from R15 243 in 1960 in the mining industry and R11 972 in the manufacturing industry, to R53 682 in 1992 in the mining industry and R35 208 in the manufacturing industry. This is a clear indication that the capital intensity of the South African economy is increasing at a high rate. Dombusch \& Fischer (1998: 64) identified additional measures of capital-intensity, namely the capital-output ratio and the incremental capitaloutput ratio. The capital-output ratio is defined as the ratio between the value of the capital stock and the value of annual output.

Within the field of financial management, Ross, Westerfield, Jordan \& Firer (1996: 60) refer to the asset turnover ratios as measures used to determine the efficiency with which assets are utilized. In this regard they distinguish between the fixed asset turnover and the net asset turnover. The former refers to the efficiency of the fixed assets, while the latter refers to the efficiency of net assets. Ross et al. (1996: 84) also referred to the capital intensity ratio, which is described as the amount of assets needed to generate $R 1$ in sales. The higher the ratio, the more capital intensive the firm. This ratio is the reciprocal of the net asset turnover. It is calculated by dividing total assets by sales.

Walsh (1996: 72-74) identifies the two prime subsidiary ratios of return on total assets as the margin on sales percentage and the sales to total assets ratio. He states that the latter ratio looks at the total sales achieved by the company in relation to its total assets, a measure whose contribution to return on total assets is just as powerful and important as the profit margin. The return on total assets is considered to be the most important driver of return on equity. Walsh (1996: 78) uses the sales to total assets ratio as an indicator of the level of investment required to support any given level of sales. He shows that research into top UK companies in 1992 revealed that both retailing and manufacturing sectors had high sales to asset ratios, but that it was more pronounced in retailing.

Although 'chemicals and stores' both had sales to asset ratios that were approximately $20 \%$ above the average, this advantage was mostly offset by their lower margins. 'Brewing' and 'health care' had ratios that were less than 1 . The brewing sector required $\$ 1.60$ of assets to support $\$ 1.00$ of sales. Although the sales to total assets ratio of the health sector is also below average, this sector has a margin on sales that compensates by almost $200 \%$ for the somewhat high assets. In contrast, the high margins in 'brewing' were still not sufficient to pay for the very high investment in assets in this sector (Walsh, 1996: 78).

It is interesting to note that Walsh (1996: 84-87) identifies drivers of both margin on sales and sales to total assets. In the case of the sales margin, the following cost ratios are identified as drivers: materials/sales; labour/sales; factory over- heads/sales; and administrative and selling costs/sales. To improve the sales margin, one or more of the cost percentages must fall. In the case of the sales to total assets ratio, he identifies the following ratios as drivers: sales/fixed assets; sales/ inventories; and sales/accounts receivable. Walsh furthermore states that the sales to fixed assets ratio

'is one of the strong determinants of company performance and is heavily influenced by the nature of the industry. It is, therefore, less amenable to management action than are many of the other performance drivers. For many years, it has been difficult for very capital-intensive sectors of industry to earn high returns, except where there has been some element of monopoly' (1996: 92).

Van Horne (1997: 704) defines the asset turnover ratio as sales/total assets. It measures the relative efficiency with which the company utilizes its input in order to generate output. It varies according to the type of company being studied. He also refers to the total assets to sales ratio (total assets/ sales) as a measure of operating efficiency. The lower this ratio, the more efficient the utilization of assets. It is the reciprocal of the total asset turnover ratio (Van Horne, 1997: 744).

Riahi-Belkaoui (1992) investigated the concept of value added-based ratio analysis. Value added represents the total return of the firm whereas the traditional financial analysis concentrates more on net income. In this context, total return refers to the sum of the returns for all the stakeholders of the firm, and not just to the returns for the owners, as measured by net income. Value added is calculated as sales minus bought in materials and services. Alternatively, it is equal to depreciation of fixed assets plus dividends paid plus net interest paid plus salaries and wages plus taxation plus retention of earnings. Riahi-Belkaoui suggested the following ratios be used:

- Managerial efficiencies: value added/total assets; value added/shareholders' equity; value added/cost of input of labour and capital.

- Productive efficiency: value added/sales; value added/salaries and wages; value added/machine hours; value added/ employees.

- Contribution to total return: salaries and wages/value added; net income after tax/value added; taxation/value added; depreciation/value added; interest/value added.

\section{Research method}

The Graduate School of Business, University of Stellenbosch maintains a number of financial databases. These include, amongst others, a database on value added statements and one on the annual financial statements (balance sheet, income statement and cash flow statement). Data in these databases are standardised to allow for meaningful comparisons. It was decided to only use data on companies in the Industrial Section for the period 1991 to 1997 . To be included in the sample, the company must have published a value added statement in 1997. If a company published a value added statement up to 1996, but did not publish a value added statement in 1997, the company was excluded from the sample. The reason for the inclusion of value added statements lie in the use of value added as a factor in the measurement of capital intensity. 
Four sub-samples were defined:

A: Companies that published value added statements for the full period of 1991-1997 (referred to as FULCI).

B: Companies that started to publish value added statements any time during 1991-1997 (includes companies in subsample $A$ ) (referred to as $A L C I$ ).

C: Companies in A that provide employee data (referred to as EFUL).

D: Companies in B that provide employee data (referred to as EMPAL)

The following ratios for capital intensity were calculated for sub-samples $\mathbf{A}$ to $\mathbf{D}$ :

- Fixed assets/total assets (fata): The higher this ratio, the more capital-intensive the company. Capital-intensive companies are considered to have more fixed assets relative to current assets. Total assets are calculated as fixed assets plus other assets plus current assets.

- Sales/total assets (salta): The lower this ratio, the more capital-intensive the company.

- Sales/fixed assets (salfa): The lower this ratio, the more capital-intensive the company. This ratio is analogue to the previous ratio and it is expected that identical results will be achieved.

- Depreciation as \% of sales (dep): The higher this ratio, the more capital-intensive the company. The annual depreciation of fixed assets for capital-intensive companies are expected to be higher relative to sales than non-capital-intensive companies.

- Fixed assets/value added (fava): The higher this ratio, the more capital-intensive the company. It is measured as the ratio of the book value of fixed assets relative to value added. It is also referred to as the capital-output ratio.

- Salaries/sales (salsa): The lower this ratio, the more capital-intensive the company.

- Salaries/cost of sales (salcos): The lower this ratio, the more capital-intensive the company.

The following ratios were calculated additionally for subsamples $\mathbf{C}$ and $\mathbf{D}$ :

- Fixed assets per employee(faemp): The higher this ratio, the more capital-intensive the company.

- Value added per employee(vaemp): The higher this ratio, the more capital-intensive the company.

- Salaries/value added (salva): The lower this ratio, the more capital-intensive the company.

The following statistical analyses were executed for the variables (ratios) per sub-sample:

- Descriptive statistics.

- Ranking of companies per measure of capital intensity.

- Test for differences between rankings of ratios for total sub-sample.

- Test for differences between rankings of ratios based on sectors.

- Test for differences between rankings of ratios based on years.

- Test for differences in rankings of ratios between sectors.

- Test for differences between rankings of ratios within sectors.

Due to the fact that a high ratio could in some instances refer to high capital-intensity while in other cases it could refer to low capital-intensity, it was decided to compare the rankings of the ratios to test for significant differences between the ratios. This has the advantage that outliers do not influence the results. Furthermore, as the data to be analysed are ordinal level data, non-parametric tests were used to test for differences. In this regard the following tests were used:

- Kruskal-Wallis test

- Wilcoxon matched pair test

- Mann-Whitney test

Only the p-values for the differences between variables were noted. Tests for significant differences were conducted at the $5 \%$ significance level.

In order to test $\mathrm{H}_{1}$ (significant differences between rankings of the ratios), the ratios for the total databank per sub-sample were compared with one another. For this test the Wilcoxon test was used. The test for $\mathrm{H}_{2}$ (significant differences between rankings of ratios based on sectors) required that the Kruskal. Wallis test be used. This was also the case for testing $\mathrm{H}_{3}$ (significant differences between rankings of ratios based on financial years). For testing $\mathrm{H}_{4}$ (significant differences in rankings of ratios between sectors), the database per sub-sample was grouped per ratio, whereafter the significance of differences between sectors were tested using the MannWhitney test. The test for $\mathrm{H}_{5}$ (significant differences between the rankings of ratios within sectors) required the Wilcoxon test. This required the data to be grouped per sector, whereafter the test for significant differences between the rankings of ratios were executed per sector.

The data were grouped into the following sectors. (The sector numbers are used as set out in the database of the USB. Sectors 16-20 and 37 do not exist.):

- Sector 15: Industrial Holding

- Sector 21: Beverage, Hotels \& Leisure

- Sector 22: Building \& Construction

- Sector 23: Chemicals, Oils \& Plastics

- Sector 24: Clothing, Footwear \& Textiles

- Sector 25: Food

- Sector 27: Furniture, Household \& Allied

- Sector 28: Engineering

- Sector 29: Electronics \& Electrical

- Sector 30: Motor

- Sector 31: Packaging \& Printing (including Sappi)

- Sector 32: Pharmaceutical \& Medical

- Sector 33: Media

- Sector 34: Steel \& Allied

- Sector 35: Transport

- Sector 36: Stores

- Sector 38: Development Stage

\section{Results}

The results of the investigation are presented in the sequence of the analyses done. Due to a lack of space, only the results of ALCI and EMPAL will be provided in this article. The complete set of results is available from the first-mentioned author. The discussion of results, however, will also refer to the results of FULCI and EFUL.

\section{Descriptive statistics}

The descriptive statistics of the various sub-samples are set out below. The statistics for ALCI are as set out in Table 1. The descriptive statistics for EMPAL are as in Table 2. 
Table $1 \mathrm{ALCl}$ descriptive statistics

\begin{tabular}{lccccccccc}
\hline Variable & Mean & Median & Minimum & Maximum & $\begin{array}{c}\text { Lower } \\
\text { quartile }\end{array}$ & $\begin{array}{c}\text { Upper } \\
\text { quartile }\end{array}$ & $\begin{array}{c}\text { Std. } \\
\text { Dev }\end{array}$ & $\begin{array}{c}\text { Coefficient of } \\
\text { variation }\end{array}$ & $\begin{array}{c}\text { Unit of } \\
\text { measurement }\end{array}$ \\
\hline Fata & 38.88 & 36.46 & 1.10 & 96.65 & 23.18 & 52.41 & 20.62 & 53.03 & $\%$ \\
salta & 1.68 & 1.56 & 0.14 & 8.39 & 1.13 & 1.96 & 0.91 & 54.17 & $\times$ \\
salfa & 7.71 & 4.58 & 0.29 & 126.35 & 2.50 & 8.67 & 11.62 & 150.71 & $\times$ \\
dep & 3.11 & 2.33 & 0.21 & 27.53 & 1.56 & 3.51 & 2.99 & 96.14 & $\%$ \\
fava & 0.97 & 0.75 & 0.05 & 6.09 & 0.42 & 1.19 & 0.83 & 85.57 & $\times$ \\
salsa & 20.53 & 19.75 & 3.07 & 55.64 & 13.96 & 25.73 & 8.76 & 42.67 & $\%$ \\
salcos & 22.69 & 21.94 & 3.20 & 92.39 & 15.42 & 28.80 & 10.08 & 44.42 & $\%$ \\
\hline
\end{tabular}

Table 2 EMPAL descriptive statistics

\begin{tabular}{lccccccccc}
\hline Variable & Mean & Median & Minimum & Maximum & $\begin{array}{c}\text { Lower } \\
\text { quartile }\end{array}$ & $\begin{array}{c}\text { Upper } \\
\text { quartile }\end{array}$ & $\begin{array}{c}\text { Std. } \\
\text { Dev }\end{array}$ & $\begin{array}{c}\text { Coefficient of } \\
\text { variation }\end{array}$ & $\begin{array}{c}\text { Unit of } \\
\text { measurement }\end{array}$ \\
\hline fata & 39.40 & 39.52 & 2.48 & 96.65 & 23.37 & 52.41 & 20.44 & 51.88 & $\%$ \\
salta & 1.64 & 1.57 & 0.14 & 8.39 & 1.14 & 1.95 & 0.83 & 50.61 & $\times$ \\
salfa & 7.02. & 4.30 & 0.29 & 100.78 & 2.49 & 8.25 & 8.57 & 122.08 & $\times$ \\
dep & 316 & 2.39 & 0.24 & 25.69 & 1.63 & 3.56 & 2.98 & 94.30 & $\%$ \\
fava & 1.01 & 0.77 & 0.05 & 6.09 & 0.43 & 1.19 & 0.86 & 85.15 & $\times$ \\
salsa & 20.47 & 19.82 & 3.07 & 55.64 & 14.14 & 25.49 & 8.43 & 41.18 & $\%$ \\
salcos & 22.58 & 21.95 & 3.20 & 92.39 & 15.66 & 28.44 & 9.68 & 42.87 & $\%$ \\
faemp & 92.19 & 45.87 & 1.85 & 2412.88 & 26.14 & 92.35 & 177.82 & 192.88 & $R^{\prime} 000$ \\
vaemp & 79.65 & 65.30 & 10.26 & 553.68 & 46.31 & 96.31 & 55.38 & 69.53 & $R^{\prime} 000$ \\
salva & 63.22 & 63.73 & 24.86 & 257.81 & 54.73 & 71.50 & 15.24 & 24.11 & $\%$ \\
\hline
\end{tabular}

Although the detail of FULCI and EFUL are not provided, similar trends exist between ALCI and FULCI, as well as between EMPAL and EFUL.

Given the fact that one is a sub-sample of the other, this is to be expected. The most obvious difference between ALCI and FULCI is the difference in the maximum value of salcos, with that of $\mathrm{ALCI}$ equal to $92.39 \%$, and that of FULCI equal to $57.81 \%$. The maximum value of dep also differs, with that of ALCI being $27.53 \%$ and that of FULCI $20.63 \%$. Other than this, the two sub-samples present quite similar descriptive statistics. What is also interesting, is the measure of coefficient of variation (C.V.) The range of this ratio, which relates standard deviation to the mean to make comparison possible, is quite extensive. It is obvious that the ratios differ substantially in their degree of homogenity. Both sub-samples present the same phenomenon in that the C.V. of salfa, dep and fava are considerably higher than the other four ratios. The C.V. of salfa is actually quite in a league of its own.

When comparing the descriptive statistics of EMPAL and EFUL, the same observations as above can be made. Furthermore, the three additional ratios calculated for these two subsamples are equally interesting. The difference between EMPAL and EFUL in terms of these three ratios are practically negligible. The C.V. of faemp is also quite extreme, while the C.V. of salva of EMPAL is the lowest of all the ratios of any sub-sample. When comparing all four sub-samples with one another, it is also clear that the differences (with a few excep- tions already noted) are negligible. It is equally obvious that the ratios with a very high C.V. are those in which fixed assets play a role (salfa, dep, fava, faemp).

\section{Results of rankings}

For the purposes of this analysis, each of the sub-samples were sorted respectively for each of the ratios. They were ranked on an annual base, which means that a company could feature more than once during the period 1991-1997. The forty most capital-intensive companies per ratio per subsample and the forty least capital-intensive companies were listed. The results for ALCI are as in Appendix A and B respectively. As ALCI entails the total database from which the other sub-samples were compiled, it will be analysed in detail before moving on. The variables as ranked were renamed with an $R$ preceding the name of the variable, to denote the ranked variable. Due to this, the variable fata becomes Rfata, salta becomes Rsalta, et cetera.

In Appendix A (most capital-intensive companies) it is interesting to note the predominance of sector 21 (Beverages, Hotels \& Leisure) in Rfata, and to a lesser extent in Rsalta and Rsalfa. Sector 25 (Food) also figures prominently. However, both these sectors lose their prominence in Rdep, where sector 35 (Transport) is the sector with the greatest visibility. Sector 21 and sector 22 (Building \& Construction) both have seven (7) appearances after sector 35's 13. In Rfava, there is no one sector that dominates the ratio. Sector 21 does lead the ratio, with sector 31 (Packaging \& Printing) coming to the fore. However, one must bear in mind that Sappi is part of 
sector 31 for the purposes of this research, and in this specific case is responsible for all seven (7) appearances. When the last two ratios, Rsalsa and Rsalcos, are analysed, three totally different sectors dominate, namely sector 36 (Stores) with 14 appearances in both cases, sector 30 (Motor) with 8 and 10 appearances respectively, and sector 23 (Chemicals, Oils \& Plastics) with 8 and 9 appearances respectively. It is therefore clear that different sectors feature in the respective ratios. From this it can be suggested that the different ratios do not all measure the same phenomenon (in this case capital-intensity).

When analysing Appendix B (least capital-intensive companies), further interesting observations can be made. In Rfata no single sector dominates the rankings. Three sectors, namely sector 27 (Furniture, Household \& Allied), sector 29 (Electronics \& Electrical) and sector 30 (Motor) lead the number of appearance with 9 appearances each. Sector 36 (Stores) is a close second with 8 appearances. None of these sectors figured prominently in respect of Rfata in Appendix A. Rsalta is dominated by two sectors, namely sector 36 (Stores) with 23 appearances, and sector 30 (Motor) with 14 appearances. Sectors 36 and 30 again dominate Rsalfa, with 11 and 14 appearances respectively. This is also the case for Rdep. In Rfava, the dominating sectors are sector 29 (Electronics \& Electrical) - 11 appearances; sector 30 (Motor) - 9 appearances; sector 36 (Stores) - 8 appearances, and sector 27 (Furniture, Household \& Allied) -7 appearances. In Rsalsa, totally different sectors dominate the list of appearances, namely sector 32 (Pharmaceutical \& Medical) - 9 appearances: sector 38 (Development Stage) - 9 appearances; sector 35 (Transport) - 7 appearances; and sector 24 (Clothing, Footwear \& Textiles) - 6 appearances. In Rsalcos a similar trend is observed. Again, as stated previously, different sectors dominate the different ratios, which suggests that the different ratios do not all measure the same phenomenon for individual companies.

When comparing Appendices A and B with each other, some interesting observations are made. Sectors 30 and 36 dominate Rsalsa and Rsalcos on the list of most capital-intensive companies. However, on the list of least capital-intensive companies, these two sectors figure quite prominently in the following ratios: Rfata, Rsalta, Rsalfa, Rdep, Rfava. They do not figure at all in Rsalsa and Rsalcos, which is to be expected given the fact that they are deemed to be capital-intensive in respect of these two ratios. This can be interpreted in one of three ways:

- The different ratios do not measure the same phenomenon (point already made).

- There is a dualism in respect of companies being low on capital-intensity in respect of the extent to which they rely on fixed assets, while at the same time they are paying out a low $\%$ of sales in the form of salaries.

- The sectors are not homogeneous, but are diversified.

The second option suggests that a non-capital-intensive company is not necessarily a labour-intensive company when the latter is expressed in terms of salaries to sales or salaries to costs. The two forms (capital-intensive versus labour-intensive) are therefore not necessarily mirror images of each other.
Individual companies that appear on the two lists (high capital-intensive in terms of Rsalsa and Rsalcos, and low capitalintensive in terms of Rfata, Rsalta, Rsalfa and Rdep), are, amongst others, the following: Micor Industrial, LA Retail, Omega, Mustek, Brian Porter Holdings, Combined Motor Holdings, Cashbuild, Metro Cash \& Carry, Shoprite and Redgewoods Holdings.

When analysing Rfava, it is apparent that the same companies appear on both Appendices A and B, whilst some sectors also appear on both the lists. However, these are the exception rather than the rule. Examples of companies appearing on both are Cullinan Hotel and JD.

The FULCI sub-sample was drawn up to investigate only those companies of ALCI that published value added statements for the full period of 1991 to 1997 , in order to establish whether a different picture was presented. One finds similar results as in the case of ALCI. The dualism that was reported in ALCI, is also present in FULCI. Sectors that figure on the list of most capital-intensive sectors in terms of Rsalsa and Rsalcos that also figure on the list of least capital-intensive sectors in terms of Rfata, Rsalta, Rsalfa and Rdep, are sectors 29 (Electronics and Electrical), 30 (Motor), and 36 (Stores). Companies that demonstrate this dualism include Bidvest, Omega Holdings, Brian Porter Holdings, Combined Motor Holdings, Cashbuild, Metje and Ziegler, and Metro Cash and Carry. In respect of Rfava of FULCI, JD repeated its dual listing.

As stated earlier, EMPAL is a sub-sample of ALCI and includes all the companies of ALCI that published employee data. The aim of this step was to determine ratios of capital intensity based on employees. However, the majority of the ratios (7) remain as for ALCI. As EMPAL is a sub-sample of ALCI, one would expect similar trends as for ALCI. The rankings for EMPAL was done and the results are as in Appendices $C$ and $D$ for the most capital-intensive and least capital-intensive companies respectively.

In Appendix C (most capital-intensive companies-EMPAL) it is clear that similar trends to Appendix A exist, with a few minor differences. In Rsalta, sector 21 (Beverages, Hotel \& Leisure) decreased its listing from 14 in Appendix $A$ to 9 appearances. In Rdep, sector 35 (Transport) decreased its listing from 13 to 7 appearances. Rsalsa had two noteable changes, with sector 30 (Motor) decreasing from 8 in Appendix A to three appearances, and sector 36 (Stores) increasing from 14 in Appendix $A$ to 17 appearances. Rsalcos exhibits the same trend with sector 30 decreasing from 10 in Appendix A to 4, and sector 36 increasing from 14 in Appendix A to 17 appearances. In the new ratios, Rfaemp, Rvaemp and Rsalva, sector 23 (Chemicals, Oils \& Plastics) dominate in all of them. Sector 23 is also prominent in Rsalsa and Rsalcos.

In terms of Appendix D (least capital-intensive companies - EMPAL), the results are quite similar to those of ALCl. Differences include the following: in Rsalta and Rdep sector 30 (Motor) decreased its listings from 14 in Appendix B to 7 appearances; in Rsalsa sector 32 (Pharmaceutical \& Medical) decreased from 9 in Appendix B to 0 appearances. Whereas sector 23 dominated in Appendix $C$ in terms of Rfaemp, Rvaemp and Rsalva, sector 24 (Clothing, Footwear \& Textiles) is by far the prominent sector in Appendix D in terms of these three ratios. 
When comparing Rsalsa and Rsalcos of Appendix C with Rfata, Rsalta, Rsalfa and Rdep of Appendix D, similar trends as in ALCI and FULCI are observed. Companies that are noted in both groups include Micor Industrial, Bidvest, Metje and Ziegler, Siltek, Brian Porter Holdings, Metro Cash and Carry, Cashbuild and Redgewoods. In respect of the new ratios, the following was observed:

- Cullinan Hotel featured on Appendix C in Rfaemp, as well as on Appendix D in Rfata.

- Companies that featured on Appendix $C$ in respect of Rvaemp as well as on Appendix $D$ in respect of $R$ fataRdep, include Dimension Data, Home Choice and Siltek.

- This was also the case for Home Choice in respect of Rsalva on Appendix C and Rfata-Rdep on Appendix D.

The trend of dualism is therefore quite robust in terms of composition of sub-samples.

EFUL is a sub-sample of EMPAL, and includes those companies which published a full set of value-added statements from 1991 to 1997. One should expect similar results as for EMPA. The results in respect of the most capital-intensive companies are quite similar to those in EMPA, except for the ratios of Rsalsa and Rsalcos which are closer to the results of ALCI than for EMPA. The results in respect of the least capital-intensive companies are similar to those in EMPA, with minor differences here and there. The dualism reported elsewhere is also apparent in EFUL.

The dualism reported refers to the phenomenon that companies are listed as being most capital-intensive in respect of Rsalsa and Rsalcos, while also listed as being least capital-intensive in respect of Rfata, Rsalta, Rsalfa and Rdep. This is also the case in respect of sectors listed. However, a cursory glance at the appendices also reveals that this dualism reported also runs from $\mathrm{Rfata}$, Rsalta, Rsalfa and Rdep on the most capital-intensive list to Rsalsa and Rsalcos on the least capital-intensive list. The possible explanations hereof are as for ALCI.

\section{Results of tests for significant differences between rank- ings}

The results of the tests that were executed to test for significant differences between rankings, will be presented in the sequence of the tests done.

Tests for differences between rankings of ratios within each sub-sample

Tests were conducted per sub-sample to determine whether significant differences exist between the ratios within each sub-sample. Note that the results reported are the p-values of the significance of the differences. A p-value $<0.05$ indicates a significant difference between the ratios. The results are as follows:

- ALCI: No significant differences between the variables, except between Rsalta and Rsalfa and Rsalsa and Rsalcos. See Table 3.

- FULCI as for ALCI.

- EMPAL: No significant differences between the rankings of the ratios, except between Rsalta and Rsalfa, and between Rsalsa and Rsalcos. See Table 4.

- EFUL: As for EMPAL.

From Tables 3 to 4 it can be concluded that there are no significant differences between the rankings of the respective ratios, except between Rsalta and Rsalfa, and between Rsalsa and Rsalcos. This is slightly contrary to the comparisons done on the top 40 listings. It must be borne in mind however, that

Table $3 \mathrm{ALCl}$ : Test for differences between variables: 1991-1997

\begin{tabular}{lccccccc}
\hline Variables & Rfata & Rsalta & Rsalfa & Rdep & Rfava & Rsalsa & Rsalcos \\
\hline Rfata & $*$ & 0.65 & 0.99 & 0.97 & 0.99 & 0.70 & 0.55 \\
Rsalta & 0.65 & $*$ & 0 & 0.23 & 0.42 & 0.72 & 0.82 \\
Rsalfa & 0.99 & 0 & $*$ & 0.84 & 0.07 & 0.87 & 0.96 \\
Rdep & 0.97 & 0.23 & 0.84 & $*$ & 0.91 & 0.82 & 0.85 \\
Rfava & 0.99 & 0.42 & 0.07 & 0.91 & $*$ & 0.96 & 0.85 \\
Rsalsa & 0.70 & 0.72 & 0.87 & 0.82 & 0.96 & $*$ & 0 \\
Rsalcos & 0.55 & 0.82 & 0.96 & 0.85 & 0.85 & 0 & $*$ \\
\hline
\end{tabular}

Table 4 EMPAL : Test for differences between variables : 1991-1997

\begin{tabular}{|c|c|c|c|c|c|c|c|c|c|c|}
\hline Variables & Rfata & Rsalta & Rsalfa & Rdep & Rfava & Rsalsa & Rsalcos & Rfaemp & Rvaemp & Rsalva \\
\hline Rfata & * & 0.10 & 0.41 & 0.68 & 0.60 & 0.92 & 0.98 & 0.91 & 0.87 & 0.65 \\
\hline Rsalta & 0.10 & $*$ & 0 & 0.39 & 0.42 & 0.73 & 0.83 & 0.39 & 0.44 & 0.65 \\
\hline Rsalfa & 0.41 & 0 & * & 0.90 & 0.16 & 0.85 & 0.93 & 0.65 & 0.78 & 0.88 \\
\hline Rdep & 0.68 & 0.39 & 0.90 & $*$ & 0.85 & 0.89 & 0.90 & 0.58 & 0.90 & 0.96 \\
\hline Rfava & 0.60 & 0.42 & 0.16 & 0.85 & * & 0.95 & 0.95 & 0.97 & 0.93 & 0.85 \\
\hline Rsalsa & 0.92 & 0.73 & 0.85 & 0.89 & 0.95 & * & 0 & 0.50 & 0.36 & 0.39 \\
\hline Rsalcos & 0.98 & 0.83 & 0.93 & 0.90 & 0.95 & 0 & * & 0.71 & 0.54 & 0.90 \\
\hline Rfaemp & 0.91 & 0.39 & 0.65 & 0.58 & 0.97 & 0.50 & 0.71 & $*$ & 0.38 & 0.80 \\
\hline Rvaemp & 0.87 & 0.44 & 0.78 & 0.90 & 0.93 & 0.36 & 0.54 & 0.38 & * & 0.99 \\
\hline Rsalva & 0.65 & 0.65 & 0.88 & 0.96 & 0.85 & 0.39 & 0.90 & 0.80 & 0.99 & $*$ \\
\hline
\end{tabular}


the statistical analyses were done for the total database per sub-sample. The results show that the one ratio basically tells the same story as the other, when considered in total.

Tests for differences between rankings of ratios based on sectors

The results of these tests are reported in Tables 5 to 6 . Note that the p-values are reported. Where a p-value $<0.05$ it indicates a significant difference between the rankings.

Table 5 Test for differences between variables based on sectors

\begin{tabular}{lcc}
\hline Variables & ALCI & FULCI \\
\hline Rfata & 0 & 0 \\
Rsalta & 0 & 0 \\
Rsalfa & 0 & 0 \\
Rdep & 0 & 0 \\
Rrava & 0 & 0 \\
Rsalsa & 0 & 0 \\
Rsalcos & 0 & 0 \\
\hline
\end{tabular}

Table 6 Test for differences between variables based on sectors

\begin{tabular}{lcc}
\hline Variables & EMPAL & EFUL \\
\hline Riata & 0 & 0 \\
Rsalta & 0 & 0 \\
Rsalfa & 0 & 0 \\
Rdep & 0 & 0 \\
Rfava & 0 & 0 \\
Rsalsa & 0 & 0 \\
Rsalcos & 0 & 0 \\
Rfaemp & 0 & 0 \\
Rvaemp & 0 & 0 \\
Rsalva & 0 & 0 \\
\hline
\end{tabular}

From Tables 5 and 6 it is clear that the rankings of the different ratios differ significantly when compared on a sectoral level. This is to be expected, as the different sectors are compiled with the issue of homogenity in mind.

Tests for differences between rankings of ratios based on years

The results of these tests are reported in Tables 7 and 8 . The p-values of the tests are reported. Where a p-value $<0.05$ it indicates a significant difference between the rankings.

Table 7 shows that in respect of $\mathrm{ALCI}$ and FULCI, there are no significant differences in the rankings of all the ratios based on years. This means that the rankings of Rfata of 1991 does not differ significantly from the other years. This is the case for all the ratios investigated for ALCI and FULCI. What this means is that the rankings of the ratios did not change significantly over the period of investigation.

Table 8 indicates that, except for Rfaemp and Rvaemp, the rankings of the ratios of EMPAL and EFUL do not differ sig-
Table 7 Test for differences between variables based on years : 1991-1997

\begin{tabular}{lll}
\hline Variables & $\mathrm{ALCl}$ & FLLCI \\
\hline Rfata & 0.31 & 0.93 \\
Rsalta & 0.83 & 0.87 \\
Rsalfa & 0.82 & 0.99 \\
Rdep & 0.67 & 0.91 \\
Rfava & 0.86 & 0.97 \\
Rsalsa & 0.34 & 0.73 \\
Rsalcos & 0.43 & 0.78 \\
\hline
\end{tabular}

Table 8 Test for differences between variables based on years : 1991-1997

\begin{tabular}{lcc}
\hline Variables & EMPAL & EFUL \\
\hline Rfata & 0.15 & 0.80 \\
Rsalta & 0.99 & 0.92 \\
Rsalia & 0.61 & 0.98 \\
Rdep & 0.80 & 0.91 \\
Rfava & 0.82 & 0.96 \\
Rsalsa & 0.54 & 0.77 \\
Rsalcos & 0.57 & 0.79 \\
Rfaemp & 0 & 0 \\
Rvaemp & 0 & 0 \\
Rsalva & 0.24 & 0.47 \\
\hline
\end{tabular}

nificantly over time. What is interesting is the significant difference in the rankings of Rfaemp and Rvaemp for both EMPAL and EFUL. The reasons for this requires further research that falls outside the scope of this article. It does mean that in terms of faemp and vaemp. there were significant changes in the rankings. One can therefore say that some companies became more and others less capital-intensive in respect of faemp and vaemp over time.

\section{Tests for differences in rankings of ratios between sectors}

Previously tests were done to determine the significance of differences between rankings of ratios based on sectors. It was determined that there were significant differences in the rankings of ratios between sectors. This section determines the significance of differences between the rankings of each sector within each ratio. This test can be seen as an extension of the test done previously. The statistical results are available from the first-mentioned author.

In spite of the fact that there are significant differences between the rankings of the ratios based on sectors, it is quite evident that for each ratio, there are instances where there are no significant differences in the rankings of the ratios between sectors. For example, in sub-sample ALCI for ratio $\mathrm{R}$ fata, there are significant differences in the rankings between sectors 15 and $21(\mathrm{p}=0)$, but none between sector 15 and $22(p=0.87)$. Other than the fact that overall there are significant differences in the ratios between sectors, there are no specific trends to be observed in the rankings within sectors. 
Test for differences between rankings of ratios within sectors For the purposes of this test, the ratios were compared with one another within each sector per sub-sample. The statistical results are available from the first-mentioned author.

From the results it appears that overall there are significant differences within each sector between the rankings of the respective ratios. This is interesting as one would expect the sector to be homogeneous in respect of the rankings of the ratios. For example, in ALCI in sector 21 , it is clear there are significant differences in the rankings of the ratios. One would have expected no significant differences in the same sector between Rsalta and Rsalfa. Yet in sectors 15 to 31, 33, 35 and 36 of ALCI there are significant differences. Similarly, one would have expected no significant differences in the same sector between Rsalsa and Rsalcos. Yet, this is only the case for sectors $23,25,27,29,31,32,33,35$ and 36 of ALCI. In the other eight sectors there are significant differences. This phenomenon is probably attributable to the fact that sectors are not as homogeneous as generally thought.

In sector 25 of FULCI, it is only between the rankings of Rsalsa that there are no significant differences between the ratios. The rest of the rankings of the ratios all differ significantly. On the other hand, in sector 22 of FULCI there are no significant differences between the rankings of the ratios. Why the rankings of sector 22 (Building \& Construction) should not differ significantly, whilst the rankings of sector 25 (Food) does, defies logic. The only possible reason is that the sectors are not compiled homogeneously.

This absence of a logical trend between the rankings of the ratios within sectors, is continued in EMPAL and EFUL. In these two sub-samples, three additional ratios are calculated. Yet the same phenomenon is observed in the rankings of these three ratios as well. This reinforces the argument in favour of sectors constructed in a haphazard manner.

\section{Conclusion}

The following conclusions in respect of the hypotheses stated can be drawn from the above:

- $\mathrm{H}_{1}$ (There are significant differences between the rankings of the ratios) is rejected for the majority of the ratios at the 0.05 level.

- $\mathrm{H}_{2}$ (There are significant differences between the rankings of the ratios based on sectors per sub-sample) is accepted at the 0.05 level.

- $\mathrm{H}_{3}$ (There are significant differences between the rankings of the ratios based on years per sub-sample) is rejected for all but Rfaemp and Rvaemp at the 0.05 level.

- $\mathrm{H}_{4}$ (There are significant differences in the rankings of the ratios between sectors per sub-sample) delivers a mixed bag of results.

- $H_{5}$ (There are significant differences between the rankings of the ratios within sectors per sub-sample) also delivered a mixed bag of results.

As stated in the introduction, the objective of this research was to get an indication of the degree of capital-intensity of selected companies listed in the Industrial Section of the JSE, and, where possible, to identify trends. The hypotheses as stated were investigated and the results produced reported. Possible reasons for the significant differences between the rankings of ratios where none were expected, include the following (as stated elsewhere):

- The different measures of capital-intensity are of such a nature that they will produce unexpected results.

- There is a dualism in that companies are capital-unintensive on some measures and capital-intensive on others.

- The sectors are not homogeneous.

- Valuation of assets.

- Age of assets et cetera.

As stated, a company that is not capital-intensive is not necessarily labour-intensive in terms of salaries/sales.

When the descriptive statistics are brought into the picture, some more light is shed upon the lack of clear trends or even contradictory evidence. Salta and salfa were expected to produce similar results. However, they do not. A possible reason for this lies in the fact that the degree to which companies commit themselves to fixed assets, differ greatly. The concept of operating leverage which measures this phenomenon comes to mind. This possibility is borne out by the coefficient of variation of salfa and dep which greatly exceeds that of salta. This is due to the variability of fixed assets.

In conclusion, it is clear that overall there are no significant differences between the rankings of the ratios. When viewed with:n the context of sectors, there are significant differences between the rankings of the ratios. Within the context of years, there are no significant differences in the rankings of ratios. The results show that within sectors there are also significant differences between the ratios. This is also the case when the rankings are tested between sectors per ratio.

\section{References}

Dornbusch, R. \& Fischer, S. 1998. Macro-Economics, $3^{\text {rd }}$ Ed. Johannesburg: Lexicon Publishers.

Garrison, R.H. \& Noreen, E.W. 1997. Managerial accounting, $8^{\text {th }}$ Ed. Boston: Irwin/McGraw-Hill.

Riahi-Belkaoui, A. 1992. Value added reporting: lessons for the United States. Westport. Connecticut: Quorum Books.

Ross, S.A., Westerfield, R.W.. Jordan. B.D. \& Firer, C. 1996. Fundamentals of corporate finance, 1st SA Ed. London: Irwin.

Shapiro, E. 1982. Macroeconomic analysis, $5^{\text {th }}$ ed. New York: Harcourt Brace Jovanovich, Inc.

Van Horne, J.C. 1997. Financial management and policy. $11^{\text {th }} \mathrm{Ed}$. London: Prentice-Hall.

Walsh, C. 1996. Key management ratios. London: Financial Times; Pitman Publishing. 


\begin{tabular}{|c|c|c|c|c|c|c|c|c|c|c|c|c|c|c|}
\hline & & & & & & Most Capital-Int & ntensive C & & & & & & & \\
\hline Rfata & & Rsalta & & Rsalfa & & Rdep & & Rfava & & Rsalsa & & Rsalcos & & \\
\hline COMPANY & $\operatorname{SEC} Y$ & $\begin{array}{l}\text { R COMPANY } \\
\end{array}$ & SEC YR & COMPANY & $\operatorname{SEC} Y$ & \begin{tabular}{l|l} 
YR & COMPANY \\
\end{tabular} & SEC YR & COMPANY & SEC YR & COMPANY & SEC YR & COMPANY & SEC YR & \\
\hline SUN INTERNATIONAL & 21 & \begin{tabular}{l|l|l|}
93 & TRENCOR \\
\end{tabular} & $\begin{array}{ll}35 & 91\end{array}$ & GRIFFIN & 15 & 94 AVIS HOLDINGS & $\begin{array}{ll}21 & 97\end{array}$ & UNISPIN HOLDINGS & $\begin{array}{ll}24 & 92\end{array}$ & ENGEN & $23 \quad 96$ & 6 & 239 & \\
\hline CITY LODGE HOTELS & 21 & 97 GRIF FIN & 15 & GRIFFIN & 15 & 95 GRIFFIN & 15 & GRIFFIN & 15 & ENGEN & 23 & 7 ENGEN & & \\
\hline SUN INTERNATIONAL & 21 & 92 GRIFFIN & 1595 & TRENCOR & 35 & 91 GRIFFIN & 15 & GRIFFIN & $15 \quad 95$ & ENGEN & 23 & 1 MICOR INDUSTRIAL & & \\
\hline SUN INTERNATHONAL & 29 & 94 GRIFFIN & 1597 & GRIFFIN & 15 & 97 GRIFFIN & 15 & SAPPI & $\begin{array}{ll}31 & 92 \\
-12\end{array}$ & MICOR INDUSTRIAL & 15 & 5 ENGEN & 239 & \\
\hline SUN INTERNATIONAL & 21 & 95 CULLINAN HOTEL & 21 & CITY LODGE HOTELS & 21 & 97 TELLOY HOLDINGS & 21 & CAFCA & 29 & ENGEN & 23 & 5 ENGEN & & \\
\hline CROOKES BROTHERS & 25 & 95 SAPPI & 31 & CULLINAN HOTEL & 21 & 97 TELJOY HOLDINGS & $21 \quad 91$ & SAPPI & 31 & ENGEN & 23 & 3 ENGEN & 23 & \\
\hline CROOKES BROTHERS & 25 & 91 STOCKS HOTELS & 21 & CITY LODGE HOTELS & 21 & 94 TELJOY HOLDINGS & $21 \quad 94$ & GRIFFIN & $15 \quad 97$ & ENGEN & 23 & 4 ENGEN & 23 & 94 \\
\hline CROOKES BROTHERS & 25 & 94 CITY LODGE HOTELS & 21 & CITY LODGE HOTELS & 21 & 96 TELLOY HOLDINGS & 21 & ENGEN & 23 & MICOR INDUSTRIAL & 15 & $6 /$ MICOR INDUSTRLAL & & \\
\hline SUN INTERNATIONAL & 21 & 97 ALPHA & 22 & SAPPI & 31 & 95 ALPHA & 22 & SAPPI & $31 \quad 93$ & ENGEN & 23 & 2 ENGEN & 23 & \\
\hline CITY LODGE HOTELS & 21 & 94 CITY LODGE HOTELS & 21 & CROOKES BROTHERS & 25 & 94/ALPHA & 22 & ALPHA & 2291 & MUSTEK & 29 & 37 COMBINED MOTOR HOLOINGS & 30 & \\
\hline SUN INTERNATIONAL & 21 & 96 FITY LODGE HOTELS & 21 & CROOKES BROTHERS & 25 & 91 ALPHA & 22 & ENGEN & 23 & COMBINED MOTOR HOLDINGS & 30 & 35 MUSTEK & & \\
\hline CROOKES BROTHERS & 25 & 92 ALPHA & 22 & CROOKES BROTHERS & 25 & 93 AUTOPAGE HOLDINGS & 29 & SAPPI & 31 & COMBINED MOTOR HOLDINGS & 30 & 36) COMBINED MOTOR HOLDINGS & 30 & \\
\hline CITY LOOGE HOTELS & 21 & 96 CROOKES BROTHERS & 25 & ALPHA & 22 & 91 AUTOPAGE HOLDINGS & 29 & ENGEN & 23 & OMEGA HOLDINGS & 29 & COMBINED MOTOR HOLDINGS & & 94 \\
\hline GRIFFIN & 15 & 95 CROOKES BROTHERS & 25 & CROOKES BROTHERS & 25 & 92 AUTOPAGE HOLDINGS & 29 & CROOKES BROTHERS & 25 & METRO CASH AND CARRY & 36 & 97/METRO CASH AND CARRY & 36 & \\
\hline CITY LODGE HOTELS & 21 & 35 CROOKES BROTHERS & 25 & CITY LODGE HOTELS & 21 & 95 HIGHVELD STEEL & 34 & SAPPI & 31 & COMBINED MOTOR HOLDINGS & 30 & 34 OMEGA HOLOINGS & 29 & \\
\hline CROOKES BROTHERS & 25 & 83] SAPPI & 31 & ALPHA & 22 & 92 AUTOPAGE HOLDINGS & 29 & ALPHA & 22 & METRO CASH AND CARRY & 36 & 32/METRO CASH AND CARRY & & \\
\hline SUN INTERNATIONAL & 21 & 1 CROOKES BROTHERS & 25 & CROOKES BROTHERS & 25 & 96 HIGHVELO STEEL & 34 & CROOKES BROTHERS & 25 & METRO CASH AND CARRY & 36 & 95 METRO CASH AND CARRY & 36 & \\
\hline KERSAF INVESTMENTS & 21 & 33 ALPHA & 22 & ALPHA & 22 & 93/ALPHA & 22 & KERSAF INVESTMENTS & 21 & 3 METRO CASH AND CARRY & 36 & 96/METRO CASH AND CARRY & 36 & \\
\hline GRIFFIN & 15 & 94 CITY LODGE HOTELS & 21 & SAPPI & 31 & 91 TELJOY HOLDINGS & $21 \quad 95$ & CROOKES BROTHERS & 25 & METRO CASH AND CARRY & 36 & 34/METRO CASH AND CARRY & & \\
\hline TELJOY HOLOINGS & 21 & 93 CROOKES BROTHERS & 25 & CROOKES BROTHERS & 25 & 95 HIGHVELO STEEL & $34 \quad 92$ & SAPPI & 31 & METRO CASH AND CARRY & 36 & 93 METRO CASH AND CARRY & 36 & 93 \\
\hline GRIFFIN & 15 & 97/SAPPI & 31 & CROOKES BROTHERS & 25 & 97|PUTCO & 35 & CITY LODGE HOTELS & 21 & COMBINED MOTOR HOLDINGS & 30 & 97 COMBINED MOTOR HOLOINGS & 30 & \\
\hline KERSAF INVESTMENTS & 21 & Y2 CROOKES BROTHERS & $25 \quad 97$ & SAPPI & 31 & 92 HIGHVELD STEEL & $34 \quad 94$ & CROOKES BROTHERS & $25 \quad 92$ & OMEGA HOLDINGS & 29 & 96 COMBINED MOTOR HOLDINGS & 30 & \\
\hline SAPP| & 31 & 31 NETWORK HEAL THCARE & $32 \quad 97$ & SUN INTERNATIONAL & 21 & 93 UNITRANS & $\begin{array}{ll}35 & 93\end{array}$ & CITY LODGE HOTELS & $21 \quad 94$ & MICOR INDUSTRIAL & 15 & 97 OMEGA HOLDINGS & 29 & \\
\hline CROOKES BROTHERS & 25 & 36 LION MATCH CO. & $\begin{array}{ll}15 & 96\end{array}$ & SUN INTERNATIONAL & 21 & 92 UNITRANS & 35 & ENGEN & 23 & COMBINED MOTOR HOLDINGS & 30 & 93 MICOR INDUS TRIAL & 15 & \\
\hline TELJOY HOLOINGS & 21 & 3 LION MATCH CO. & $\begin{array}{ll}15 & 95 \\
-1\end{array}$ & KERSAF INVESTMENTS & 21 & 97 HIGHVELD STEEL & $34 \quad 95$ & SAPPI & 31 & METRO CASH AND CARRY & 36 & 91) METRO CASH AND CARRY & 36 & \\
\hline ALPHA & 22 & 11. LION MATCHCO. & 15 97 & KERSAF INVESTMENTS & 21 & 93 UNITRANS & $\begin{array}{ll}35 & 95 \\
\end{array}$ & CULLINAN HOTEL & 21 & REDGWOODS HOLDINGS & 36 & 97 COMBINED MOTOR HOLDINGS & 30 & \\
\hline TELJOY HOLDINGS & 21 & 1 SAPPI & 31 & SAPPI & 31 & 93 UNITRANS & 35 & ALPHA & 22 & COMBINED MOTOR HOLDINGS & 30 & REDGWOOOS HOLDINGS & 36 & \\
\hline TELLOY HOLDINGS & 21 & 4 CROOKES BROTHERS & 25 & NETWORK HEAL THCARE & 32 & 97|ALPHA & 22 & ENGEN & 23 & CASHBUILD & 36 & COMBINED MOTOR HOLDINGS & 30 & \\
\hline CROOKES BROTHERS & 25 & 17) KERSAF INVESTMENTS & 21 & SUN INTERNATIONAL & 21 & 94|PUTCO & 35 & Jo & 27 & COMBINED MOTOR HOLDINGS & 30 & 91 BRIAN PORTER HOLDINGS & 30 & \\
\hline KERSAF INVESTMENTS & 21 & 7 ALPHA & 22 & STOCKS HOTELS & 21 & 97 UNITRANS & 35 & ENGEN & 23 & CASHBUILD & 36 & 93 CASHBUILD & 36 & \\
\hline SUNCRUSH & 21 & 3 SAPPI & 31 & ALPHA & 22 & 94 UNITRANS & 35 & SUN INTERNATIONAL & 21 & LA RETAIL & 24 & 97 CASHBUILD & 36 & \\
\hline ALPHA & 22 & 2 | KERSAF INVESTMENTS & 21 & SUN INTERNATIONAL & 21 & 95 UNITRANS & 35 & KERSAF INVESTMENTS & 21 & CASHBUILD & 36 & 94 CASHBUILD & 36 & \\
\hline CLINIC HOLDINGS & 32 & 3] UNISPIN HOLDINGS & 24 & KERSAF INVESTMENTS & 21 & 94/PUTCO & 35 & MIGHVELO STEEL & 34 & BRIAN PORTER HOLOINGS & 30 & 96 CASHBUILD & 36 & \\
\hline SUNCRUSH & 21 & 4 AVIS HOLDINGS & 21 & KERSAF INVESTMENTS & 21 & $92 \mid$ PUTCO & 35 & SUN INTERNATIONAL & 21 & CAFCA & 29 & 94 SHOPRITE(TRADEGRO) & 36 & \\
\hline QUTOPAGE HOLDINGS & 29 & 1 KERSAF INVESTMENTS & 21 & SAPPI & 31 & 94|ALPHA & 22 & CITY LODGE HOTEIS & 21 & CASHBUILD & 36 & 92 BIDVEST GROUP & 15 & 94 \\
\hline SUNCRUSH & 21 & 6] SUN INTERNATIONAL & 21 & KERSAF INVESTMENTS & 21 & $95 \mid$ PUTCO & 35 & CROOKES BROTHERS & 25 & BIDVEST GROUP & 15 & 94 CASHBUILD & 36 & \\
\hline QLPHA & 22 & 3 KERSAF INVESTMENTS & 21 & KERSAF INVESTMENTS & 21 & 96 PUTCO & 35 & GRINCOR & 15 & SHOPRITE(TRADEGRO) & 36 & 97 BRIAN PORTER HOLOINGS & 30 & 97 \\
\hline HLH & 25 & 5 KERSAF INVESTMENTS & 21 & HLH & 25 & 94 TELJOY HOLOINGS & 21 & HLH & 25 & CASHBUILD & 36 & 95 BRIAN PORTER HOLDINGS & 30 & \\
\hline KERSAF INVESTMENTS & 21 & 1) SUN INTERNATIONAL & 21 & ALPHA & 22 & 95 UNISPIN HOLDINGS & 24 & KERSAF INVESTMENTS & 21 & SIL TEK & 29 & 97 HOECHST SOUTH AFRICA & 23 & 97 \\
\hline ASER TRANSPORT & 35 & 7 ALPHA & $22 \quad 95$ & SASOL & 23 & 93 CERAMIC INDUSTRIES & $22 \quad 96$ & SAFREN & $\begin{array}{ll}15 & 93 \\
3\end{array}$ & HOECHST SOUTH AFRICA & 23 & 97 HOECHST SOUTH AFRICA & 23 & \\
\hline
\end{tabular}


APPENDIX B

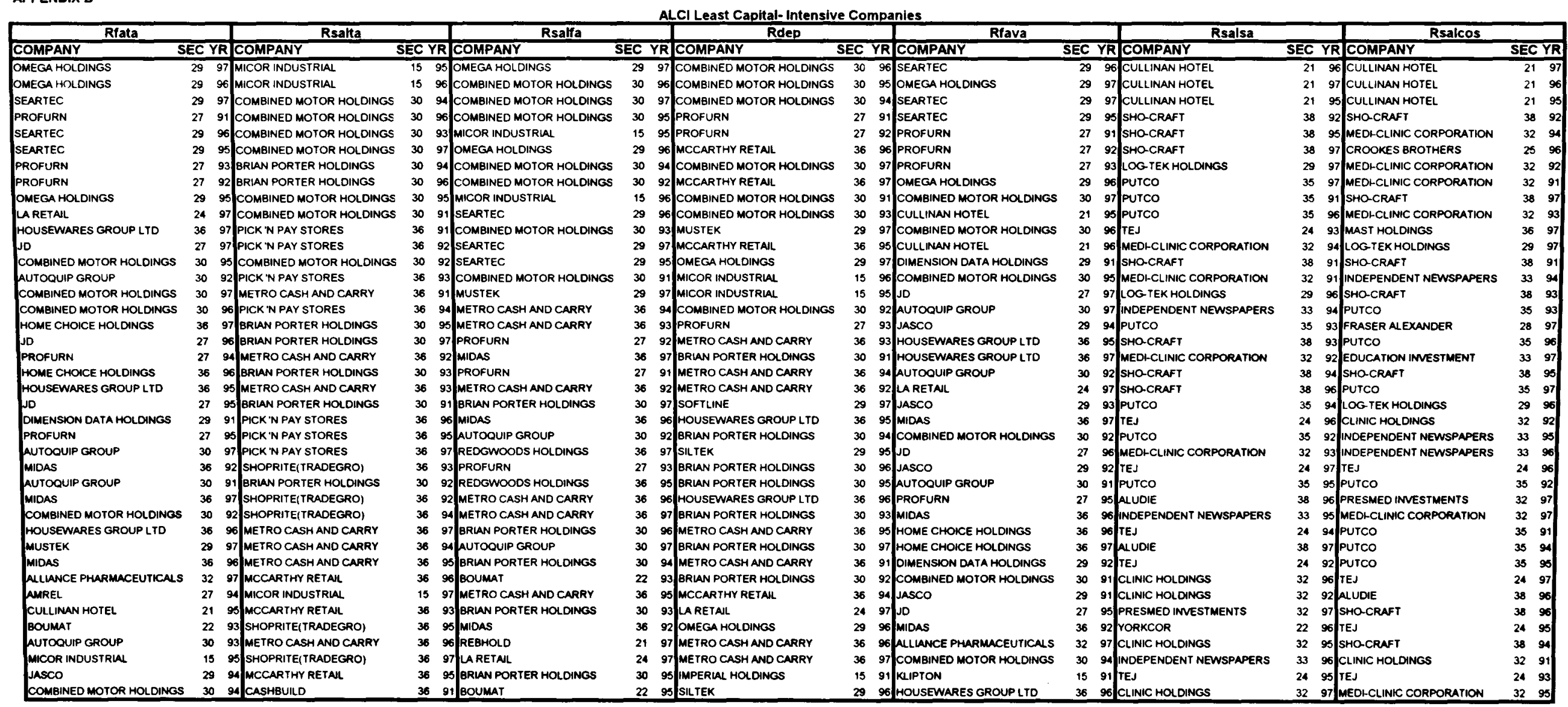


APPENDIX C

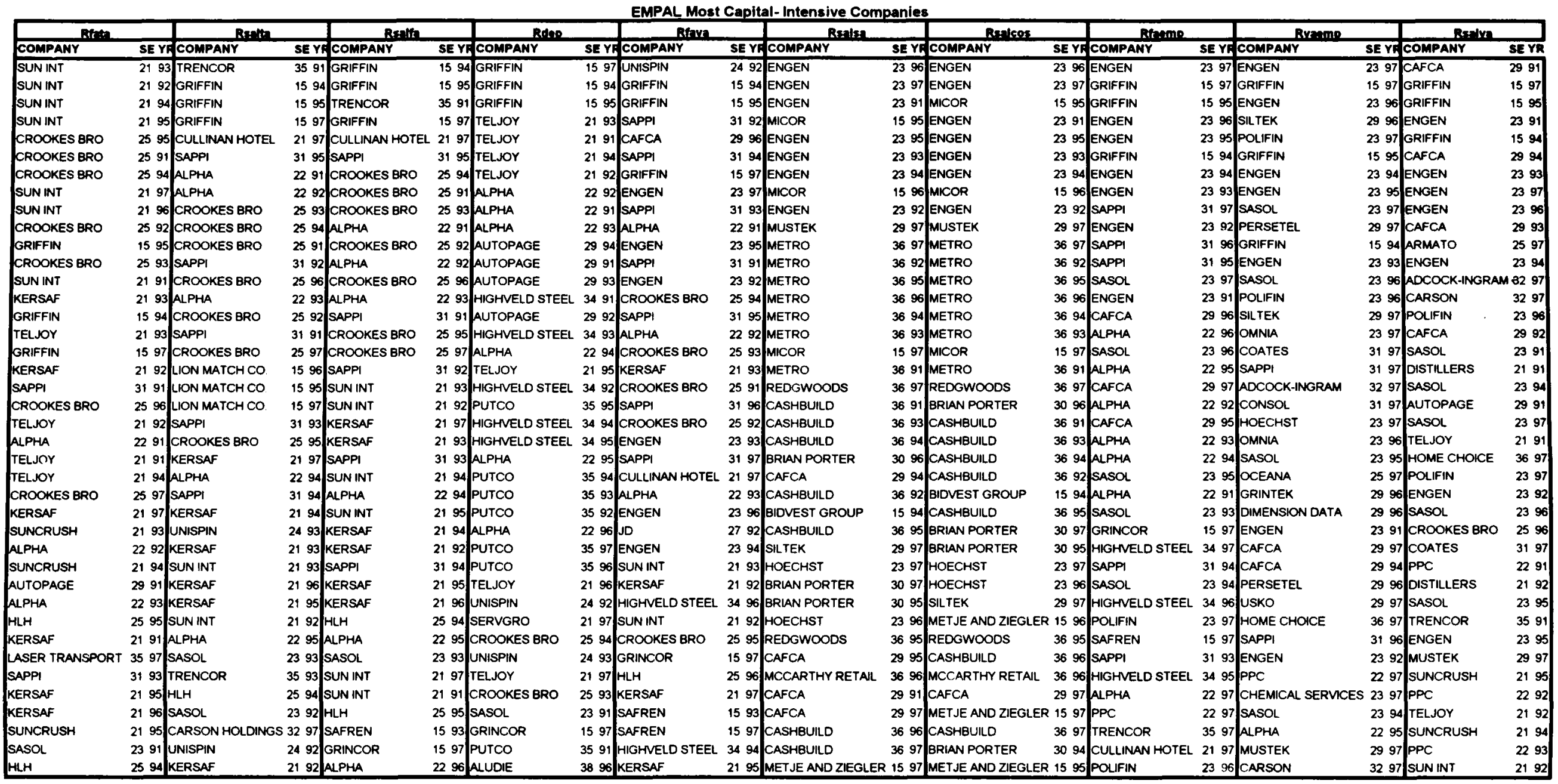


EMPAL Least Capital- Intensive Companies

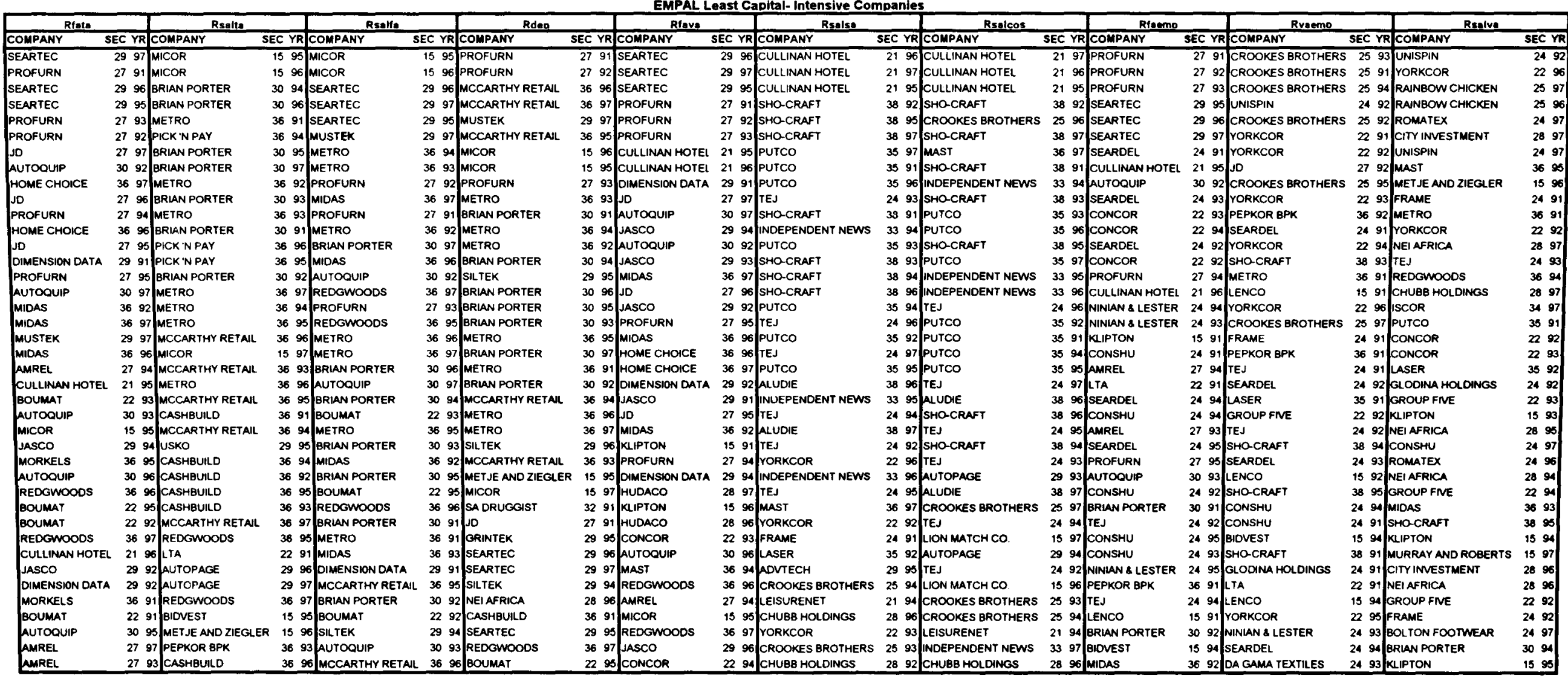

